\title{
EL ENSAYO COMO GÉNERO O HACIA LA SUPERACIÓN DE LA DISTINCIÓN ENTRE EL LENGUAJE CIENTÍFICO Y EL LENGUAJE LITERARIO
}

\author{
A. L. S. HENRIQUE \\ Instituto Federal de Educação, Ciência e Tecnologia do Rio Grande do Norte \\ ana.henrique@ifrn.edu.br \\ Submetido em $27 / 08 / 2018$ e aceito em 17/02/2020 \\ DOI: $10.15628 /$ holos. 2020.7672
}

\section{RESUMEN}

Este ensayo discute el género textual ensayo, a partir de Gómez-Martínez (1981), Arenas Cruz (1997) Adorno (1998), buscando entre los hallazgos de esos investigadores, lo que es característico de ese género em tela. Trata-se, por lo tanto, de um estudio bibliográfico de talante cualitativo. Según estos autores, el ensayo es un género que reemplaza la sistematización científica por una ordenación estética; existe la presencia entera de su escritor en forma de reflexiones; hay el hecho de que la mayoría de las veces el ensayo no se preocupa con hallazgos novedosos, sino en examinar de forma novedosa lo corriente; tiene un carácter explorador y asimismo asistemático, y, paradoxalmente, obedece a criterios lógicos. El ensayo tiene una función social concreta: replantear críticamente los fundamentos de la realidad en todas sus dimensiones, desde los aspectos más nimios a los más trascendentales. Por ello, sus temas son los más variados, siempre dentro del ámbito de lo humano, o sea, donde predominan los valores y las opiniones.

PALABRAS-CLAVE: ensayo, género textual, lenguaje científico, lenguaje literario.

\section{O ENSAIO COMO GÊNERO TEXTUAL OU EM BUSCA DE SUPERAR A DISTINÇÃO ENTRE A LINGUAGEM CIENTÍFICA E A LINGUAGEM LITERÁRIA.}

\section{RESUMO}

Este artigo discute o ensaio enquanto gênero textual, a partir de Gómez-Martínez (1981), Arenas Cruz (1997) e Adorno (1998), buscando, nos estudos desses pesquisadores, as características desse gênero em questão. Trata-se, pois, de um estudo bibliográfico de cunho qualitativo. Segundo esses autores, o ensaio é um gênero que troca a sistematização científica por uma ordenação estética; existe, no ensaio, a presença inteira de seu escritor na forma de reflexões; há também a questão de o ensaio, geralmente, não se preocupar com o essencialmente novo, mas com examinar de forma nova o que é comum; tem também um carácter explorador e, ao mesmo tempo, assistemático, obedecendo, paradoxalmente, a critérios lógicos. O ensaio tem uma função social concreta: repensar criticamente os fundamentos da realidade em todas as suas dimensões, desde os aspectos mais simples aos mais transcendentais. Por isso, seus temas são bem variados, sempre no âmbito do humano, ou seja, onde predominam os valores e as opiniões.

PALAVRAS-CHAVE: ensaio, gênero textual, linguagem científica, linguagem literária. 


\section{PARA EMPEZAR LA DISCUSIÓN}

Para discutir sobre el ensayo, mejor que aclaremos el sitio desde donde hablamos. Santos (2002:48) afirma que

a ciência do paradigma emergente [...] é também assumidamente tradutora, ou seja, incentiva os conceitos e teorias desenvolvidos localmente a emigrarem para outros lugares cognitivos, de modo a poderem ser utilizados fora do seu contexto de origem. (Boaventura, 2002: 48)

Asimismo, según este autor, ocurre la migración entre métodos y, como

[...] cada método é uma linguagem [...] a transgressão metodológica repercute nos estilos e gêneros literários que presidem a escrita científica" [por lo tanto] "a tolerância discursiva é o outro lado da pluralidade metodológica (Boaventura, 2002: 48/49).

Así, un cambio epistemológico demanda un cambio en la forma de expresión, demanda otra expresión discursiva.

Discurso, en su sentido etimológico significa recorrido, formación, y esto se puede aplicar tanto al discurso literario como al de las ciencias. En verdad, el lenguaje literario es una experiencia de formación, que hace con que uno vea a sí mismo, a los demás y a la realidad que lo circunda de una manera distinta de la corriente porque lo hace pensar sobre lo corriente. Es decir, la experiencia de la lectura modifica al lector que vuelve a la realidad misma transformado $y$, por ello, no es adorno lingüístico. Asimismo, el discurso de las ciencias busca transformar al lector por informar y explicar la realidad. Por lo tanto, no son discursos antagónicos. Tampoco se puede decir que impere la objetividad en uno y la pura subjetividad en el otro.

La mezcla de los dos discursos, el literario y el científico, en lo que Foucault llama de ensayo, es una reflexión en la que la experiencia formadora de la lectura ficcional remite a la experiencia de lectura de teorías científicas y esta exige un retorno a la literatura en un movimiento dialógico continuo y recursivo. Como si la literatura provocase un "efecto intempestivo en el pensamiento" (Larrosa, 1998:142). O, dicho de otra forma, el ensayo puede que nazca "del descubrimiento incongruente de que la práctica literaria abre, bajo el edificio del conocimiento, un vertiginoso espacio de refracción que es necesario intentar pensar, es decir, convertir en texto". (Revel, como referido em Larrosa, 1998:142).

O, por otra, el ensayo hace como la enciclopedia china que cita Foucault en el prefacio de Las palabras y las cosas. Empieza él el apartado afirmando que su libro nació 
de un texto de Borges, en el que el escritor cita cierta enciclopedia china donde está escrito que

$$
\begin{aligned}
& \text { los animales se dividen en a) pertenecientes al emperador, b) } \\
& \text { embalsamados, c) amaestrados, d) lechones, e) sirenas, f) fabulosos, g) } \\
& \text { perros sueltos, h) incluidos en esta clasificación, i) que se agitan como } \\
& \text { locos, j) innumerables, k) dibujados con un pincel finísimo de pelo de } \\
& \text { camello, l) etcétera, m) que acaban de romper el jarrón, n) que de lejos } \\
& \text { parecen moscas. (Borges, como referido em Foucault, 1999:1). }
\end{aligned}
$$

Añade el autor francés que el asombro que provoca tal taxonomía es nuestra imposibilidad de pensarla, o sea, de poner lado a lado seres reales, seres fantásticos y seres imaginados, los vivos y los muertos.

De lo mismo, en el ensayo, se intenta poner, lado a lado, los seres fabulosos y los reales, la voz de la ciencia y la voz de la poesía, confluir en un lenguaje único el ejercicio de la reflexión tras la experiencia de la lectura llamada científica y de la llamada narrativa de ficción, en el que ambas son discursos de formación. Es decir, se intenta caminar hacia la superación de la diferencia existente entre "el lenguaje de las disciplinas del conocimiento y los lenguajes expresivos" (Larrosa, 1998:141).

La indeterminación semántica es inherente al lenguaje mismo, sea en escritos científicos, que están ilusionados con la objetividad, sea en el lenguaje literario que asume la indeterminación misma. El lenguaje tiene en su propia constitución la indeterminación semántica, es decir, las palabras y menos aún las estructuras sintácticas no poseen una relación biunívoca entre sus significantes y significados. En verdad, tienen una vaguedad que desaparece (o casi desaparece) en el uso, en el enunciado, en la estructura textual, en el discurso, sea literario o científico. Pensar que se puede obtener esta clareza u objetividad, esta biunivocidad tanto entre pensamiento y expresión como entre expresión y comprensión, es una ilusión engañosa que se apodera de los que piensan el lenguaje de forma maniqueísta: objetividad corresponde a un único sentido y subjetividad a una pluralidad de sentidos.

Si miramos una palabra en el diccionario, por ejemplo, lo que encontramos no es su sentido, son posibilidades de sentido, son significaciones que orientan al sentido. Y el sentido es percibido sólo en la tensión del uso, en el texto, en el enunciado, sea éste un discurso científico o literario. Estamos de acuerdo con Adorno (1998) cuando este autor afirma que en el diccionario todas las significaciones son bien demasiado estrechas en comparación con los cambios en el contexto, bien demasiado vagas en comparación con los inconfundibles matices que el contexto funda en cada caso. Es decir, el contexto es el responsable por la determinación semántica, y, por lo tanto, el uso de un lenguaje cercano al literario no imputa al texto ensayístico una imposibilidad de lectura objetiva, ya que el sentido está determinado por el mismo contexto.

Dicho de otra forma, no es por utilizar un lenguaje que, como dice GómezMartínez (1981), hace incursiones en lo literario y lo autobiográfico, que el lector puede 
sacar del ensayo cualquier sentido. En ello, hay pistas que cercenan esa libertad extrema del lector, conduciéndolo a la construcción de uno y no de otro sentido. Incluso al tratarse de obras literarias esa libertad es dirigida, tal vez de una forma más débil, pero, aun así, el lector no está autorizado por el texto a construir todos los sentidos que le dé la gana. Está, eso sí, invitado a construir los significados implícitos en el texto, significados que van a estar pendientes del lector mismo y de su experiencia de lectura, sin embargo, siempre guiados por el texto.

Podemos ser aún más exigentes con la construcción del sentido y decir que éste es, en verdad, fruto de una articulación entre autor, texto, lector y contexto, y desde la perspectiva del Análisis del Discurso de línea francesa, el sentido está pendiente también de la formación discursiva en la cual está incluido el discurso. Por formaciones discursivas entendemos, con Pêcheux (1984) y Orlandi (1997), las distintas regiones, socio-históricamente construidas, que recortan o plasman el interdiscurso (la memoria del decir, el decible) y que manifiestan las diferencias ideológicas, o el modo como las posiciones del sujeto y sus lugares sociales ahí representados constituyen sentidos.

Consecuentemente, no puede el lector del género en cuestión construir los sentidos que quiera, pero está invitado a la reflexión. Y esto es lo más importante. Puede decirse, por lo tanto, que el lector del ensayo es un lector más activo que el de otros géneros, que coge las ideas del ensayista como si fuera él mismo un eslabón en la cadena de comunicación, coge la semilla y las fertiliza con su propia experiencia. O como ha escrito Ortega y Gasset, en Meditaciones del Quijote:

Yo sólo ofrezco modi res considerandi posibles maneras nuevas de mirar las cosas. Invito al lector a que las ensaye por sí mismo; que experimente si, en efecto, proporcionan visiones fecundas; él, pues, en virtud de su íntima y leal experiencia, probará su verdad o su error. En mi intención llevan estas ideas un oficio menos grave que el científico; no han de obstinarse en que otros las adopten, sino meramente quisieran despertar en almas hermanas otros pensamientos hermanos. (Ortega y Gasset, 1964:23-24).

En ese sentido, el ensayo pretende establecer una conversación con su lector, un diálogo en el que su voz no es la de la verdad absoluta, la del pensamiento cerrado, sino la de la sugerencia, la de la invitación a la reflexión, la de la apertura al otro, buscando la complicidad del lector. El ensayo, a lo mejor, más que los demás géneros, es el otro, ese otro "del que nada sé, ni nada conozco, pero con el que, a lo largo de la lectura, y a su término, seré cómplice" (Mèlich, 1998:18).

Complicidad, empero, no significa que al final de la lectura estoy conforme a todo lo que dice, y repito su misma palabra, sino que abre camino para mi propia palabra, porque las ideas expresadas en el ensayo son meras sugerencias que provocan mis ideas y las hace enfrentarse al texto leído, en un diálogo recurrente y fecundo, en una conversación en la que la voz del texto hace nacer una voz otra. 
Y si pensamos en el ensayo como una conversación, pensamos también que, conforme una conversación corriente, el ensayo necesita de la diversidad de voces, necesita que se unan las voces de la ciencia y de la poesía, porque no pretende hablar desde una verdad que busca imponerse.

\section{CARACTERÍSTICAS DEL ENSAYO}

En este punto creo necesario explicitar algunas características de este género llamado ensayo. La palabra ensayo tiene implícito en su contenido un valor genérico de prueba, de empeño o esfuerzo voluntario para conseguir algo. Aplicado a un género textual tiene la acepción de un esfuerzo crítico-reflexivo, una actitud investigativa tanteadora.

En verdad, el término ensayo ha tenido una acepción bastante borrosa a lo largo de su utilización, con una significación muy amplia que permite clasificar como perteneciente a este género toda y cualquier obra "cuya calidad estilística y contenido interesante haya merecido la atención de lectores y críticos, pero cuyo carácter no ficcional ha imposibilitado clasificarla bajo un marbete genérico conocido" (Arenas Cruz, 1997:51). Tal postura hizo del género ensayo una especie de cajón de sastre que ha difuminado los rasgos específicos de esta clase de texto.

Miguel de Montaigne, ya en 1580 con sus Essais, es probablemente el precursor del ensayo moderno seguido por Bacon, que en 1597 también publicó su obra Essays. En estos textos, lo novedoso era la propia forma discursiva, un género discursivo que "daba expresión al propio proceso del pensar de una personalidad ofrecida en todo su ser" (Arenas Cruz, 1997:50).

A lo mejor, lo más acertado es dejar hablar al padre de la criatura. Afirma Montaigne (1967), en la presentación de su obra, que el juicio es un instrumento necesario al examen de todas las cosas, por eso, él lo ejercita en toda ocasión en sus ensayos. Si se trata de una materia que no entiende, con mayor razón se sirve de él, sondeando el vado desde lejos; y luego si lo encuentra demasiado profundo para su estatura, se detiene en la orilla. Para él, el convencimiento de no poder ir más allá es signo de valor de juicio, y de los de mayor consideración. Declara que reflexiona sobre las cosas, no con amplitud sino con toda la profundidad de que es capaz, y la más das veces le gusta examinarlas por su aspecto más inusitado.

Gómez de Barquero (1924), a su vez, define el ensayo como la didáctica hecha literatura, de lo que discrepa Adorno (1998), para quien el ensayo es un género que reemplaza la sistematización científica por una ordenación estética, que en muchos casos puede parecer desorden artístico. Esta especificidad, afirma el autor, hace de él una disertación amena en vez de una investigación severa y rigurosa. Y concluye que el 
ensayo está en la frontera de dos reinos: el de la didáctica y el de la poesía, y hace incursiones del uno al otro.

En las definiciones anteriores, tenemos los rasgos más característicos del género: a) la presencia entera de su escritor en forma de reflexiones; b) el hecho de que la mayoría de las veces el ensayo no se preocupa con hallazgos novedosos, sino en examinar de forma novedosa lo corriente; c) su carácter explorador y; d) asistemático.

Sobre la presencia del ensayista en su texto, Montaigne (1967) se percata de la singularidad de su aportación y argumenta que "los autores se comunican con el mundo en extrañas y peculiares formas; yo soy el primero en hacerlo con todo mi ser, como Miguel de Montaigne, no como gramático o como poeta, o como jurisconsulto." (Montaigne, 1967:782). Por ello, el ensayo es inseparable del ensayista, sea por el alto grado de personalismo, que se puede mirar bien en la perspectiva exclusiva del punto de vista del Yo en la percepción de la realidad bien en la inclusión de contenidos emotivos originarios de la experiencia del autor, sea también por las marcas lingüísticas de primera persona, la mayoría de las veces, presentes en el texto.

El ensayista siente necesidad de decir algo, pero sabe que lo hace desde el punto de vista del yo y, por lo tanto, nos lo entrega no como algo absoluto, sino como una posible interpretación digna de ser tenida en cuenta. Por ello, el ensayo asume muchas veces un tono dialogal con el lector, con la intención de que el lector se sienta despertado por las intuiciones y sugerencias presentadas tras las reflexiones. El yo del ensayista está presente en su texto, sin disimulos. Hay indicios lingüísticos como, por ejemplo, la localización personal a través del uso del deíctico Yo y formas verbales correspondientes o la modalización de la enunciación por medio de indicadores de la actitud del autor hacia lo que dice. La argumentación no se realiza sólo a través de razonamientos, sino se incluye también la fantasía (analogías, comparaciones, metáforas...) y la elección y uso singular de los registros de la lengua común. Esta introspección del yo y el análisis que éste hace de la realidad constituye a la vez un método objetivo de conocimiento, pues "la experiencia individual puede tener valor genérico porque cada hombre encierra la forma entera de la condición humana" (Arenas Cruz, 1997:456).

También es un rasgo del ensayo el hecho de replantear problemas eternos ante los valores que individualizan y diferencian cada época de las precedentes. Es decir, el ensayista "reflexiona siempre sobre el presente, apoyado en la sólida base del pasado y con el implícito deseo de anticipar el futuro por medio de la comprensión del momento actual" (Gómez-Martínez, 1981:30). Así, el ensayo lo que hace es proponer, insinuar una interpretación inédita, nueva, o bien orientar hacia una reevaluación de valores y de ideas ya en boga. Por lo tanto, el ensayista no crea, abre ventanas para airear lo ya existente, da nueva luz a la oscuridad de lo corriente, descubre, como lo hace el poeta, 
"lo que desde mucho, mucho tiempo está ahi" ${ }^{1}$, y que los otros han descuidado o todavía no aciertan con ver. De ahí que, en esta labor de reflexión y descubierta, tan propio del pensamiento racional y del que-hacer del poeta, se mezclan los lenguajes de la ciencia y de la poesía.

Con el propósito de motivar el lector a reflexionar, el género ensayístico se incluye entre los textos argumentativos, partiendo, sin embargo, debido a sus peculiares características, de lo particular y concreto como medio para reflexionar sobre lo general y universal. Además, sus conclusiones no son definitivas, no son verdades incuestionables, sino más bien ideas personales, sugerentes, provocativas, con el objeto de estimular al lector a reflexionar por su propia cuenta. Por ello, Arenas Cruz (1997) alega que el ensayo tiene una función social concreta:

replantear críticamente los fundamentos de la realidad en todas sus dimensiones, desde los aspectos más nimios a los más trascendentales. Él asume la imposibilidad de encontrar la respuesta verdadera a determinadas cuestiones de la vida o de la cultura, pero ofrece una opinión orientadora que ilumine a sus coetáneos, colaborando así a la posible solución de los problemas. (Arenas Cruz, 1997:458).

Otro rasgo del género ensayístico es su proceso de escritura, que, desde un punto de vista tradicional, se puede decir asistemático, pues "conciente de su limitación no duda en mostrar sus ideas en el mismo proceso de adquirirlas. Confía en que alguna, aunque no sea más que una, inspire al lector en un pensamiento gemelo al de su propia alma" (Gómez-Martínez, 1981:38). Por ello, afirma Adorno (1998) que el ensayo subvierte el concepto tradicional de método y procede de un modo metódicamente ametódico. Enseña que dicho género:

asume en su propio proceder el impulso antisistemático e introduce conceptos sin ceremonias, inmediatamente, tal como los concibe y recibe. No se precisan estos conceptos sino por sus relaciones recíprocas. Pero en esto se encuentra con un apoyo en los conceptos mismos. Pues es mera superstición de la ciencia por recetas la de que los conceptos son en sí mismos indeterminados y no se determinan hasta la definición. La ciencia necesita de esa idea del concepto como tabula rasa con objeto de consolidar su pretensión al dominio, su pretensión de potencia que domina la situación exclusiva - que pone ella sola la mesa rasa. En realidad, todos los principios están previamente concretados por el lenguaje en el que se encuentran. (Adorno, 1998:252).

\footnotetext{
1 "Los poetas no inventan los poemas/El poema está en alguna parte ahí detrás/Desde hace mucho mucho tiempo está ahí/El poeta no hace sino descubrirlo." (Jan Sjacel como referido em Kundera (1987).
} 
Sin embargo, el ensayo no es a-lógico, obedece a criterios lógicos en la medida en que el conjunto de sus frases y su estructura semántica tienen que componerse congruentemente en acorde interno. Exactamente por la interrelación entre los conceptos utilizados internamente en el ensayo, el texto se constituye un todo orgánico y no una mera exposición de ideas o reflexiones desconectas. No es un hilo único que va desde un punto cero hasta el infinito, pero son hilos varios que se entretejen como en una tapicería, formando una pieza racionalmente estética y fecunda, en el sentido de que permite al lector pensar el viejo desde una nueva perspectiva. Para Adorno,

escribe ensayísticamente el que compone experimentando, el que vuelve y revuelve, interroga, palpa, examina, atraviesa su objeto con la reflexión, el que parte hacia él desde diversas vertientes y reúne en su mirada espiritual todo lo que ve y da palabra a todo lo que el objeto permite ver bajo las condiciones aceptadas y puestas al escribir (Adorno, 1998:255).

Tras estas reflexiones, finalizamos este apartado con una confesión de Paulo Freire que nos remite al proceso de acercamiento que hace el ensayista y a la forma de escribir que deja a muestra tal acercamiento. En una conferencia dictada por Paulo Freire, en Brasilia, el educador nos ha regalado una construcción metafórica acerca de su método de investigación. Decía que investigaba sus temas como alguien que come una papilla caliente, empezando por los bordes, rodeando todo el plato, "sondeando el vado des de lejos", como lo hacía Montaigne, hasta sentir que ya podría ir más lejos, y comer la comida del centro del plato.

\section{SOBRE LOS TEMAS ENSAÍSTICOS}

Respecto a los temas que pueden ser objeto de reflexión en un ensayo, Arenas Cruz (1997) aboga por la completa libertad en su elección, pero siempre dentro del ámbito de lo humano, o sea, donde predominan los valores y las opiniones. Conforme a esta posición se sitúa Gómez-Martínez (1981) al afirmar que "las reflexiones no tienen que girar necesariamente sobre temas filosóficos o literarios, cualquier aspecto es propicio siempre y cuando las consideraciones sobrepasen el plano de lo puramente mecánico." (Gómez-Martínez, 1981:31). Añade que de cualquier pretexto puede nacer un ensayo y que su efectividad será tanto mayor cuanto más cercanas a nosotros estuvieren las imágenes utilizadas en la aproximación al tema. Además, el ensayista mantiene siempre su conexión con lo concreto, con lo que nos es común en la vida cotidiana, con lo trivial y mantiene también su relación con la experiencia humana con objeto de hacer reflexionar sobre los problemas eternos de la existencia humana.

En las palabras de Gómez-Martínez (1981), 
lo original del ensayo no reside en lo nuevo de los temas tratados, sino en el tratamiento mismo; para ello, el ensayista cuenta con su propia personalidad y visión del mundo, que le individualiza; cuenta también con las circunstancias históricas de la sociedad de su época, que no sólo aporta nuevas preocupaciones, sino que igualmente modela nuevos lectores con nuevas experiencias [...] El ensayista no sólo cuenta con el día, que transcurre ante sus ojos, tiene también a su disposición los diez mil años de la humanidad para reflexionar. (Gómez-Martínez, 1981:82).

Es como si el ensayista tomara a sí el hecho de que cada generación heredase la responsabilidad de volver a replantear los problemas de la existencia del hombre y, por ello, proporcionar un nuevo enfoque más acorde a las circunstancias distintivas del momento histórico.

\section{4. ¿ENSAYO ES LITERATURA?}

Respeto a la posible consideración literaria del ensayo, Adorno (1998), uno de los primeros a considerarlo como forma, nos presenta algunos argumentos interesantes que reproduzco a continuación. Parte el autor de una crítica al positivismo científico y al idealismo filosófico alemán para los cuales el arte es irracionalidad y la ciencia es conocimiento organizado, entendiendo el conocimiento organizado como el conocimiento que versa sobre lo perenne y lo universal. Sigue su argumentación afirmando que el ensayo constituye en sí mismo una crítica de todo método científico, tanto el empírico-inductivo, como el deductivo racionalista, por oponerse a la máxima de que el orden de las cosas es el orden de las ideas, que es la regla del juego de la ciencia. Profundizando aún más sus reflexiones, Adorno establece cómo el ensayo niega tres de las cuatro reglas del método cartesiano ${ }^{2}$, que se basa en una percepción clara y distinta, objetiva (clara et distincta perceptio) y en la certeza exenta de dudas. De ahí que el ensayo, según este autor, se aleje de lo que tradicionalmente se entiende por ciencia.

\footnotetext{
${ }^{2}$ Descartes busca reglas fijas para descubrir verdades y defiende el procedimiento matemático como principio primero de su método. El filósofo expone así su método: "Creí que bastarían las cuatro siguientes [...] Fue el primero, no admitir como verdadera cosa alguna, como no supiese con evidencia que lo es [...] El segundo, dividir cada una de las dificultades en cuantas partes fuere posible y en cuantas requiere su mejor solución. El tercero, conducir ordenadamente mis pensamientos, empezando por los objetos más simples y más fáciles de conocer, para ir ascendiendo poco a poco... Y por último, hacer en todos unos recuentos tan integrales y unas revisiones tan generales que llegase a estar seguro de no omitir nada" (Descartes, 1984:49). De manera sucinta, se trata de utilizar la intuición, la deducción, la enumeración suficiente y ordenada y la claridad y distinción.
} 
Por otro lado, según Adorno, tampoco el ensayo es literatura. Por dos razones: por su medio que son los conceptos, y por su objeto que es la verdad; pero no la verdad absoluta, irrefutable, pues el ensayo subvierte la idea tradicional de verdad, sino la verdad que admite su limitación y acepta otras voces que a ella se opongan. Por ello, afirma el autor que no es intención del género ensayístico buscar lo eterno en lo perecedero.

Concluye que el ensayo es una forma necesariamente vinculada a la teoría porque sus contenidos son conceptuales, es decir, es una fusión inevitable entre forma y contenido y añade enfáticamente respecto al positivismo científico:

En la alergia a las formas como puros accidentes, el espíritu cientificista se acerca al tercamente dogmático. La palabra disparada irresponsablemente pretende ser prueba de espíritu de responsabilidad para con la cosa, y la reflexión sobre lo espiritual se convierte en privilegio del que carece de espíritu. (Adorno, 1998:248).

El ensayo no es, por tanto, literatura aunque esté plagado de la subjetividad del autor y de referencias a narrativas y experiencias personales, o aunque parta de la literatura para ad-mirar la realidad. Es, eso sí, una forma textual que plasma el tanteo investigativo que el cientificismo niega al exigir la pura objetividad y el alejamiento del autor de sus escritos.

El ensayo, por ende, permite echar una nueva mirada, no mejor que otras, sino una mirada otra sobre viejos temas. Una mirada personal, y por ello, asumidamente subjetiva, que permite un diálogo entre el texto como otro y con el lector también como otro, capaz éste de tener su palabra después de la lectura del texto. Por ello, el ensayo no habla la Verdad, propone una verdad que se sabe perecedera, porque contextualizada y circunstancial y que se sabe capaz de convivir con otras verdades.

\section{REFERENCIAS BIBLIOGRÁFICAS}

Adorno, T. W. (1998). El ensayo como forma. Pensamiento de los confines, $\mathrm{n}-1$, segundo sem. Buenos Aires: Paidós, pp.248-259.

Arenas Cruz, M. H. (1997). Hacia una teoría general del ensayo. Construcción del texto ensayístico. Cuenca: Universidad de Castilla-La Mancha.

Descartes. R. (1984). Discurso del Método, meditaciones metafísicas. Madrid: EspasaCalpe.

Foucault, M. (1999). Las palabras y las cosas. Madrid: Siglo veintiuno de España.

Gómez-Martínez, J. L. (1981). Teoría del Ensayo. Salamanca: Universidad de Salamanca.

Kundera. M. (1987). El arte de la novela. Catalunya: Tusquets Editores. 
Larrosa, J. (1998). La locura en el lenguaje. En La experiencia de la lectura. Estudios sobre literatura y formación. (2ª ed.). Barcelona: Laertes, pp. 140-165.

Mèlich, Joan-Carles. (1998). Totalitarismo y fecundidad. La filosofía frente a Auschwitz. Barcelona: Anthropos.

Montaigne, M. E. (1967). Oeuvres complètes. Bruges: Bibliothèque de la Pléiade. (Trad. Cast. de Juan G. de Lucas, Ensayos Completos. Barcelona Orbis, 1985, 3 Vols.)

Orlandi, E. P. (1997). As formas do silencio. No movimento dos sentidos. Campinas, SP: Unicamp,.

Ortega y Gasset, J. (1964). Meditaciones del Quijote. Ideas sobre la novela. Madrid: Espasa-Calpe.

Pêcheux, M. (1984). Discurso: estrutura ou acontecimento. Campinas, São Paulo: Pontes.

Sousa Santos, B. (2002). Um discurso sobre as ciências. (13a ed.) Porto: Edições Afrontamentos. 